\title{
COVID-19 Pandemic- A Review
}

\author{
Dr. Noha Laj ${ }^{1} \mid$ Abhinsha $Z^{2} \mid$ Dr. Raishy R Hussain ${ }^{3} \mid$ Aarcha B Raj ${ }^{4}$ \\ 1,2,3,4 Department of Microbiology, AJ College of Science and Technology Thonnakkal, Trivandrum, Kerala, India
}

To Cite this Article

Dr. Noha Laj, Abhinsha Z, Dr. Raishy R Hussain and Aarcha B Raj, “COVID-19 Pandemic- A Review”, International Journal for Modern Trends in Science and Technology, 6(9): 59-67, 2020.

\section{Article Info}

Received on 08-August-2020, Revised on 18-August-2020, Accepted on 27-August-2020, Published on 02-September-2020.

\section{ABSTRACT}

COVID-19 pandemic has proved to affect human population detrimentally. In the current scenario, this review article is an attempt to compile various aspects of COVID - 19 like the origin of the virus, its mode of transmission, replication, collection of samples, prevention of the disease etc. in a simple manner, understandable to the general public. There have been a lot of myths circulating about the origin of the virus, its spread, replication and this article have been compiled to deliver the accurate information.

KEYWORDS: Corona virus, structure, origin, pathogenesis

\section{INTRODUCTION}

Coronavirus is not a single but a group of related RNA viruses and is considered to be one of the largest RNA virus that have the capability of causing diseases in mammals and also in birds. They have a characteristic club shaped spike. In humans, these viruses prove to be mild to lethal causing respiratory tract infections. Mild illness includes some the common cold, while lethal illness varies from SARS, MERS, and COVID-19.

The name "coronavirus" was derived from the Latin corona, meaning "crown" or "wreath"(1). The name was first coined by June Almeida and David Tyrrell who first observed and studied about the human coronaviruses (2). Several known coronaviruses are circulating in animals that have not yet infected humans. A spill over event is when a virus that is circulating in an animal species is found to have been transmitted to human(s).

\section{Classification}

The scientific name for coronavirus is Orthocoronavirinae or Coronavirinae $(3,4,5)$. Coronaviruses belong to the family of Coronaviridae and order Nidovirales, and domain
Riboviria (6,7). They are further divided into four-alphacoronaviruses and betacoronaviruses which are capable of infecting mammals - and gammacoronaviruses and deltacoronaviruses which are capable of infecting birds (8).

\section{ORIGIN}

Bats and birds, which are warm-blooded flying vertebrates, are found to be an ideal natural reservoir for the coronavirus. Many human coronaviruses have their origin in bats (9). A possible path of evolution, of SARS coronavirus and keen bat coronaviruses, suggests that SARS related coronaviruses coevolved in bats for a long time. The ancestors of SARS-CoV first infected leaf-nose bats, subsequently and then they spread to horseshoe bats and then to civets, and finally to humans $(10,11)$. 


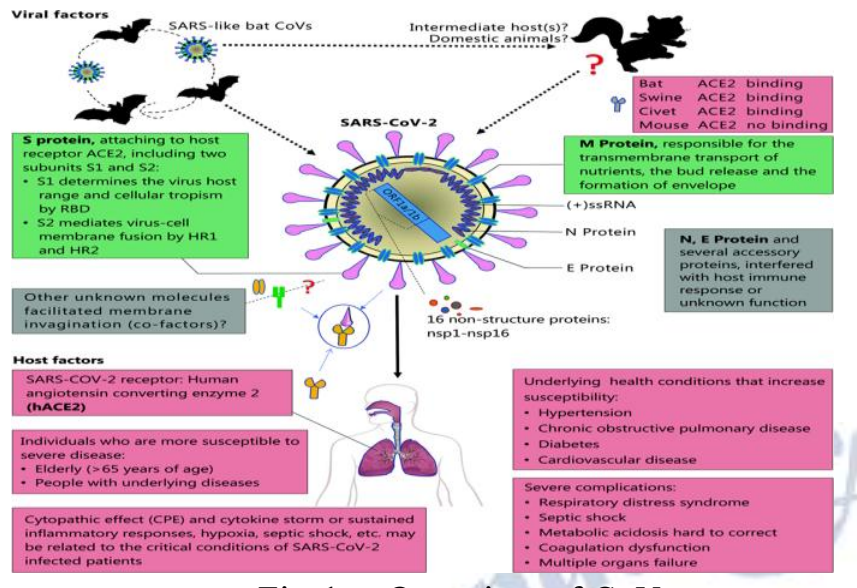

Fig.1. Overview of $\mathrm{CoV}$

\section{STRUCTURE}

They are large, spherical, and at times pleomorphic and particles with bulbous surface projections (12). The average diameter of the virus is about $125 \mathrm{~nm}$ and diameter of the envelope is about $85 \mathrm{~nm}$ and has characteristic spikes which are of $20 \mathrm{~nm}$ in length. The envelope of the virus appears as a distinct pair of electron-dense shell $(13,14)$. The viral envelope consists of a characteristic lipid bilayer, in which three different proteins like the membrane (M), envelope (E) and spike (S) structural proteins are embedded (15) at a ratio of 1:20:300 (16). A coronavirus has about 74 surface spikes (17).

Spike proteins are the visible protrusions on the surface of Corona virus, which give the characteristic, crown-like appearance. The surface spikes are homotrimers of the $\mathrm{S}$ protein, are heavily glycosylated and is composed of two subunits- S1 and S2. This protein is composed of Class I fusion protein which helps to mediate the receptor binding site and the membrane fusion between the virus and host cells. S1 subunit is the head of the spike which has the receptor binding domain (RBD) and S2 subunit forms the stem which can anchor the spike onto the viral envelope and on the activation of protease will enable fusion. The role of theses spikes is to act as a molecular key, which is achieved by recognizing and binding to specific cell-surface receptors (the locks) present on the surface of our cells, through the $\mathrm{S} 1$ receptor-binding domain. When $\mathrm{S} 1$ binds spike undergoes dramatic structural changes to alter the conformation and mediate entry of the virus into the cell. The $\mathrm{E}$ and $\mathrm{M}$ protein forms the viral envelope and helps in maintaining its structure.

The nucleocapsid inside the envelope is formed from multiple copies of the nucleocapsid $(\mathrm{N})$ protein and are bound to the positive-sense single-stranded RNA genome (18) The membrane proteins, envelope and nucleocapsid provides protection to the virus outside the host cell (19). The genome of corona viruses is approximately 26-32 kilobases.

\section{Covid-19}

The name came as such Co-Corona, vid-Virus disease, 19-2019. It is an infectious disease known to be caused by the virus, severe acute respiratory syndrome coronavirus 2 (SARS-CoV-2) (20). The disease was initially identified in the late of December 2019, a pneumonia outbreak was reported in Wuhan, the capital of Central China's Hubei province and is now recognised to have aroused from the wet markets of Wuhan. On 31 December 2019, the outbreak was identified to be that of a novel strain of coronavirus, which was called 2019-nCoV by WHO and renamed now as SARS-CoV-2 by the International Committee on Taxonomy of Viruses. The strain as now been identified as that of beta corona virus similar to SARS- CoV.

It has since then spread globally, resulting in the ongoing 2019-20 coronavirus pandemic $(21,22)$ affecting about 187 countries and territories. As of now more than about 3.5 million cases of Covid -19 have been reported and about 2,50,000 deaths have been confirmed so far. About 1.2 million have recovered from the disease. Cordon sanitaire (French word)- restriction of movement of people into or out of a well-defined geographic area to control the spread of infectious disease- were imposed by various nations. The pandemic thus resulted in the lockdown of countries and also restrictions within different states.

\section{Replication CyCle}

A. Entry

The infection begins when the spike attaches to the host cell receptor. Soon after attachment, a protease from the host cell cleaves and activates the receptor-attached spike protein. The cleavage and activation allows the virus to enter the host cell either by endocytosis or direct fusion of the viral envelop with the host membrane (23).

The virus particle gets uncoated as soon as it enters the host cell, and the genome enters the cell cytoplasm. RNA genome has a $5^{-}$methylated cap and a $3^{-}$polyadenylated tail, which allows the RNA to attach to the host cell's ribosome for translation. The host ribosome then translates the initial overlapping ORF of the virus genome and 
forms a long polyprotein which has its own proteases that cleave the polyprotein into multiple non-structural proteins (24).

\section{B. Replication}

Replicase-transcriptase protein is the RNA-dependent RNA polymerase (RdRp) and is directly involved in the replication and transcription of RNA from an RNA strand. The other non-structural proteins in the complex assist in the replication and transcription process. The exoribonuclease non-structural protein provides extra dependence to replication by providing a proofreading function which the RNA-dependent RNA polymerase does not have (25).

One of the main functions is to replicate the viral genome. RdRp directly mediates the synthesis of negative-sense genomic RNA from the positive-sense genomic RNA and is followed by the replication of positive-sense genomic RNA from the negative-sense genomic RNA (24). Another important function is to transcribe the viral genome and RdRp directly mediates the synthesis of negative-sense subgenomic RNA molecules from the positive-sense genomic RNA which is followed by the transcription of the negative-sense subgenomic RNA molecules to their corresponding positive-sense mRNAs (24).

\section{Release}

The resultant positive-sense genomic RNA now becomes the genome of the progeny viruses. The mRNAs are then translated by the host's ribosomes into the structural proteins and a number of other accessory proteins (24). RNA translation occurs inside the host endoplasmic reticulum and viral structural proteins move along the secretory pathway into the intermediate compartment of Golgi body. The M proteins direct the assembly of viruses following its binding to the nucleocapsid (24). Progeny viruses are then released from the host cell by exocytosis through secretory vesicles (24).

\section{EPIDEMIOLOGY}

\section{A. Incubation Period}

There is a delay between the moment a person is first infected and the time they develop symptoms and this is known as the incubation period. On average it takes 5-6 days from when someone is infected with the virus for symptoms to show, however it can take up to 14 days, but $97.5 \%$ of people who develop symptoms will do so within 12 days of infection (26). Some people even showed symptoms after 28 days. Minority of cases may not develop any noticeable symptoms at any point in time $(27,28)$ and remains asymptomatic but may contribute to the spread of the disease. People with mild symptoms who are otherwise healthy should self-isolate. Seek medical attention if you have a fever, a cough, and difficulty breathing. Call ahead.

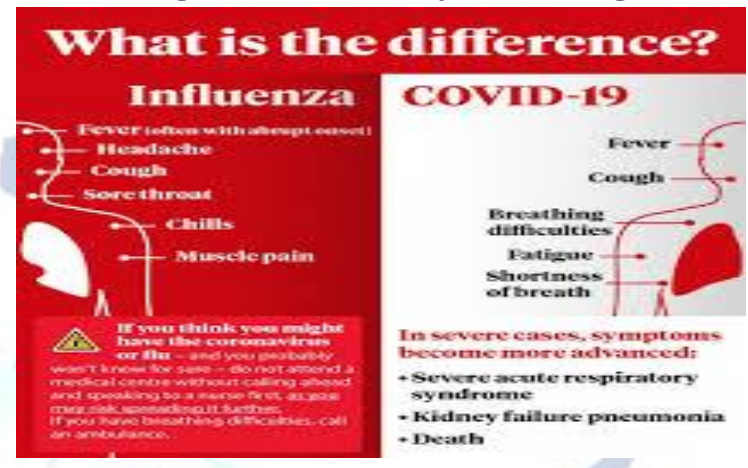

Fig.2. Difference between Influenza and Covid 19

\section{Pathogenesis}

Since SARS-CoV and SARS-CoV-2 are so similar, the biochemical interactions and their pathogenesis may also be similar. Binding of the SARS-CoV to the (ACE-2) angiotensin-converting enzyme 2 receptors in the Type- 2 pneumocytes in the lungs will trigger a cascade of inflammation in the respiratory tract [29]. When the spike protein binds to the ACE- 2 receptor, the complex will be proteolytically processed by the Type- 2 transmembrane protease TMPRSS2 thereby leading to the cleavage of ACE-2 and activation of the spike protein $(30,31)$, thereby facilitating viral entry into the target cell. It has also been suggested that the cells in which ACE-2 and TMPRSS2 are concurrently present are the ones that are most susceptible for the entry by the virus (32). Studies show that SARS-CoV-2 virus also requires ACE-2 and TMPRSS2 to enter cells (33).

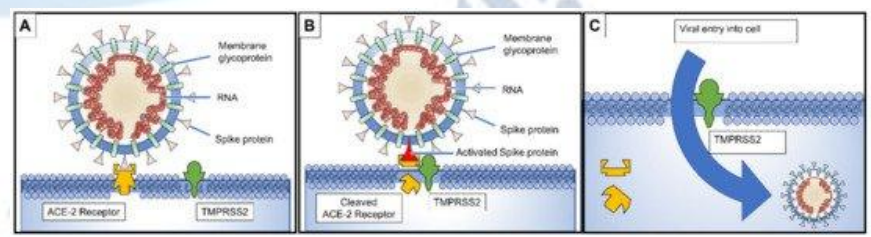

Figure 3. (A) Binding of the spike proteins to the receptors; (B) Cleaving of the receptor and activation of protein (C) Facilitation of viral entry.

Following the viral entry and cell infection the host's immune response is triggered and the inflammatory cascade is initiated by the antigen-presenting cells (APC). This process starts with the two functions of APC: 
(1) presentation of the foreign antigen to CD4+-T-helper (Th1) cells, and

(2) releasing of the interleukin-12 to further stimulate the Th 1 cell. The Th 1 cells then stimulate CD8+-T-killer (Tk) cells that will target any cells containing the foreign antigen. In addition, the activated Th1 cells also stimulate B-cells to produce antigen-specific antibodies.

\section{Clinical Presentation}

In the first published review of the clinical presentation of 41 patients admitted to hospital with COVID-19 (34), 98\% of the patients had fever, $76 \%$ had cough, and about $55 \%$ had shortness of breath on admission to the hospital. But those admitted may had less severe symptoms for 2 to 14 days prior to presentation, during which they were contagious. By the time patients developed shortness of breath, they had been sick for about an average of eight days. All patients developed clinical pneumonia supported by chest CT findings, and 13 of the 41 patients i.e., $32 \%$ developed hypoxic respiratory failure. Four patients i.e., $10 \%$ required mechanical ventilation, due to refractory hypoxia. In total, six patients died, giving a case fatality rate (CFR) of $15 \%$ and triggering panic that quickly spread worldwide.

\section{Symptoms}

Corona virus infects the lungs primarily and will develop a cough- continuous cough and if there is cough already, it may be worse than usual.

COVID-19 affected different people in different ways and most infected people developed mild to moderate symptoms like fever with temperature of $37.8^{\circ} \mathrm{C}$, shivering, loss of appetite, sputum production and tiredness. Some people may also experience aches and pains, nasal congestion, runny nose, sore throat and diarrhoea. Loss of smell and taste has also been reported in some patients. Centre for Disease Control and Prevention (CDC) in US have reported chills, repeated chills with shaking, muscle pain, headache etc. as new symptoms. In Italy the reports showed a rash like appearance in the foot of children.

\section{Complications}

Some people may progress to pneumonia, multi-organ failure, and death (35) and also neurological manifestations like seizures, stroke, encephalitis, and Guillain-Barré syndrome (36) Some of them may also develop cardiovascular-related complications including heart failure, irregular electrical activity, blood clots, and heart inflammation (37). Those of them severely affected, it may rapidly progress to acute respiratory distress syndrome (ARDS) resulting in the respiratory failure, septic shock and multi-organ failure $(38,39)$. Some other complications with COVID 19 are sepsis, abnormal blood clotting and damage to the heart (increase in prothrombin time), kidneys, and liver (elevated liver enzymes such as transaminases).

\section{TRANSMISSION}

Since the disease is a novel one, all the possible methods of transmission are yet under consideration. It is now considered to be spread during close contact, or by the inhalation of small droplets produced by the carriers or patients during coughing, sneezing, talking, or breathing (40). The droplets are transmitted, up to 1 to 2 metres and 3 to 6 feet known as airborne transmission or droplet transmission It is said that sputum and saliva carry very large amounts of virus in them. It was also identified that loud talking releases more droplets than normal talking (41). Studies also proved that an uncovered cough can lead to droplets travelling about 4.5 metres i.e. 15 feet (42).

The droplets falling to the floors or other surfaces, can infect people, by touching the contaminated surfaces and then their eyes, nose or mouth with these unwashed hands. Amount of active virus can decrease over time ultimately ceasing the infection rates (41). Experiments, proved that the virus can survive on various surfaces like copper or cardboard for more time like 4-5 hours and plastic or steel for two to three days (43). Surfaces can be decontaminated with household disinfectants thus killing the virus.

Faecal - oral route of transmission is also suspected. Though it is not a sexually transmitted infection, intimate contacts, kissing etc transmits the virus (44). Researchers in China claims that the semen of COVID-19 positive patients contained the virus. Shangai Muncipal Hospital reported this in the Jama Network Open, after examining the semen of 38 males admitted to the hospital. This was in contradictory to the earlier report presented in the Fertility and Sterility Journal, which said that after 8 days of the appearance of the symptoms, semen was tested negative of the virus. The viability of the virus is yet to be known and it is reported that these patients may be critically affected by the virus (45). Pre symptomatic 
transmission i.e. transmission before the appearance of symptoms is also observed and virus has been proved to be more contagious during the first three days after the symptoms appear. Asymptomatic transmission is also seen in certain cases (41).

\section{Sample Collection and Transport}

Special care has to be taken while collecting the samples and packing them. Different types of specimen can be collected for testing. The various specimens collected are: -

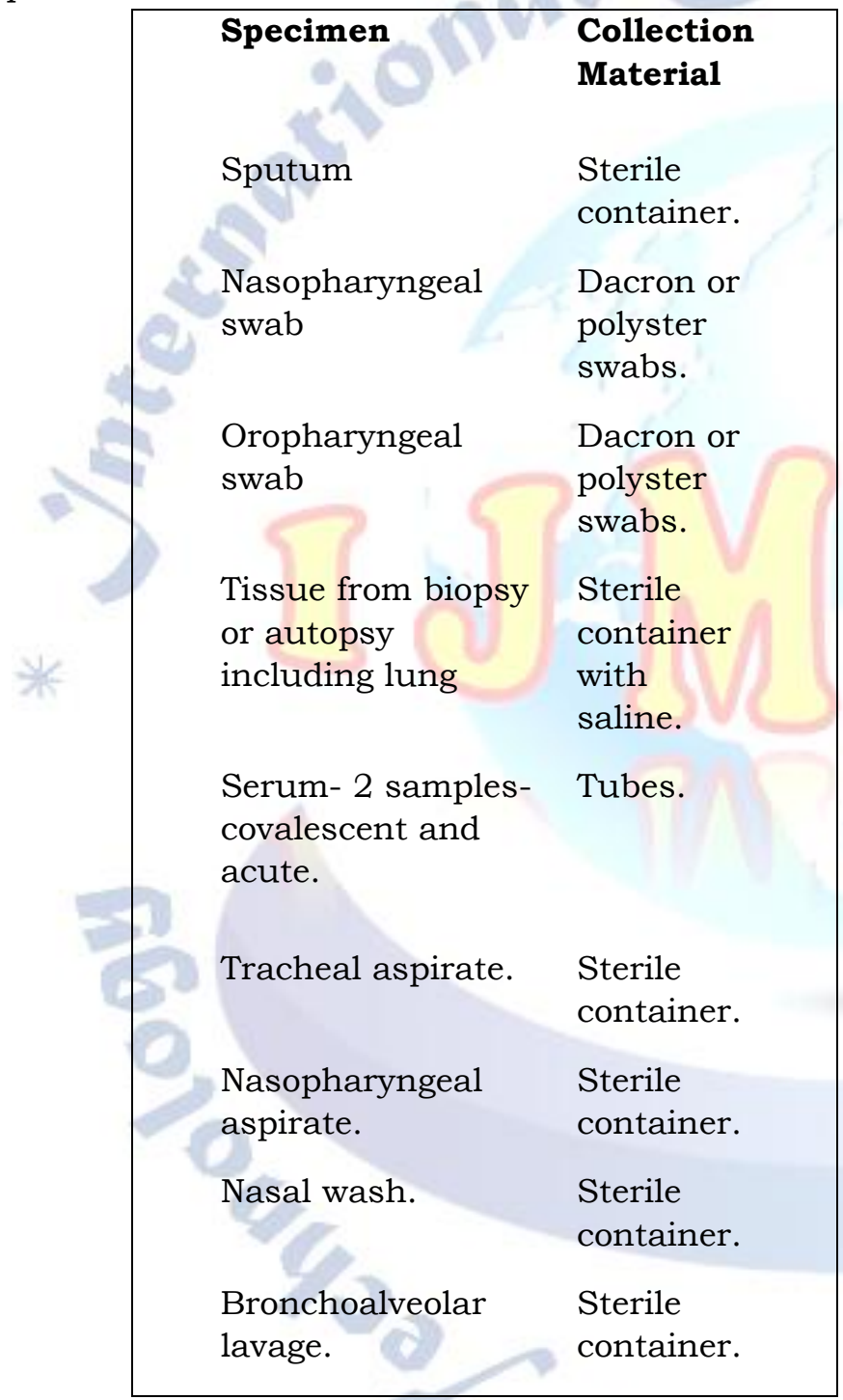

\section{Courtesy- Ministry of Personnel and TRAINING, GOVT. OF INDIA}

The specimen should be stored at $40 \mathrm{C}$ while transporting. Some of these specimens (aspirates, lavage and sputum) can be stored only till 48 hours and if required more storage time then it should be stored at $-700 \mathrm{C}$. Serum samples and swabs can be stored for 5 days and if required more, it should be kept at $-700 \mathrm{C}$. Tissues can be only stored for 24 hours at $40 \mathrm{C}$, otherwise the temperature should be increased to $-700 \mathrm{C}$.

\section{A. Steps for sealing the specimens.}

1.The specimen is then transferred to vials containing VTM- Viral Transport Medium.

2. The specimen vials are sealed using parafilm at the neck of the vial.

3. Then the vials are covered using absorbent cotton.

4. The primary vials are then placed into secondary container.

5 . The secondary container is then packed into Ziploc bags.

6. The Ziploc pouch is then placed onto a hard-plastic container, which is then sealed.

7. This container is then transferred to thermocol box filled with frozen ice packs.

8. The thermocol box is then placed into a cardboard box.

A specimen referral form and request letter are placed in a Ziploc bag and attached to the outer container, which is then sealed.

The box must be marked as Biological Substance- Category B. Handle with Care.

Note: - Personal Protective Equipment (PPE) should be worn all the time from collection to despatching for transportation.

\section{Testing Methods}

There are many technologies for COVID-19 testing, some of them are available and some are under development. There are two categories of test-one is the checking for the presence of the virus and the other is looking for the presence of antibodies as a result of viral infection. The various testing methods employed are: -

\section{A.RT-PCR}

The presence of virus can be detected by using rRT-PCR, where the viral load even in minute quantity is amplified. Respiratory samples subjected to real time reverse transcription PCR or rRT- PCR can generate the results either within hours or sometimes two days (46). Isothermal amplification assays are employed now, which does the isothermal nucleic acid amplification of the unique region of virus's RdRp gene.

\section{B. Antigen Detection}

Antigen detection test works by exposing the collected swabs to paper strips which contain artificial antibodies impregnated to it so that binding of antigens takes place. Any antigens present will bind to the strips and give a visual 
readout. But asymptomatic people who have very little nasal discharge cannot be tested here.

\section{Serology}

As part of the immune response IgM and IgG will be produced in the blood. IgM antibodies against COVID -19, will be detected in blood only several days after the initial infection but the levels are not well characterised (47), whereas IgG antibodies will become detectable only 10-14 days of infection and will in the peak state only after 28 days (48). Antibodies are slow to be present and hence they are not considered as the best markers and may be ideal only for the detection of historic infections. Most of the serological tests are only under research stage (49). Antibody tests can also be used to diagnose the healthcare workers who have been exposed to the virus and ensure that they have developed natural immunity before returning to work, as well as measuring patient immune responses to support the rapid development of an urgently-needed COVID-19 vaccine.

\section{Medical Imaging}

Radiologic findings are not found to be specific in COVID-19 patients and also chest CT are not a recommended method for routine screening.

\section{E. Pulse Oximeter}

Asymptomatic pneumonia can be diagnosed by measuring low oxygen levels using a pulse oximeter. Some doctors also report the cases of silent hypoxia with the patients who do not have shortness of breath until their oxygen levels went too low resulting in organ failure. (50) It is considered as a low cost quick diagnostic method (50). There are also technical differences in how these results are interpreted.

\section{Prevention}

\section{A. Hand washing}

Hand washing is recommended to prevent the spread of the disease. The CDC recommends that people wash hands often with soap and water for at least twenty seconds, or use an alcohol-based $(60 \%)$ sanitizer especially. This is because outside the human body, the virus is killed by household soap, which bursts its protective outer lipid layer. The WHO advises people to avoid touching the eyes, nose, or mouth with unwashed hands.

\section{B. $\quad$ Surface cleaning}

Surfaces may also be decontaminated with a number of solutions, including $62-72 \%$ ethanol, $50-100 \%$ isopropanol, $0.1 \%$ sodium hypochlorite and $0.5 \%$ hydrogen peroxide. The CDC recommends that if a COVID-19 case is suspected or confirmed at a facility such as an office or day care, all areas such as offices, bathrooms, common areas, shared electronic equipment like tablets, touch screens, keyboards, remote controls, and ATM machines used by the ill persons, should be disinfected (51).

\section{Face masks and respiratory hygiene}

The WHO has recommended healthy people wear masks only if they are at high risk, such as those who are caring for a person with COVID-19. It has also been encouraged the use of face masks or cloth face coverings more generally by members of the public to limit the spread of the virus by asymptomatic individuals. Several national and local governments have made wearing masks mandatory. Surgical masks are recommended for those who may be infected, as wearing this type of mask can limit the volume and travel distance of expiratory droplets dispersed when talking, sneezing, and coughing, whereas N-95 masks are mandatory for health workers especially, those who are in close contact with the patient and also the laboratory personnel.

\section{Social distancing}

Social distancing or physical distancing includes infection control actions intended to slow the spread of disease by minimising close contact between individuals. It includes several methods like quarantines; travel restrictions; and the closing of schools, workplaces, stadiums, theatres, or shopping centers, theatres etc. Individuals can apply social distancing by staying at home, limiting travel, avoiding crowded areas, avoiding shake hands, hugging, and physically distancing themselves from others.

Older adults (above 65) and those with underlying medical conditions such as diabetes, heart disease, respiratory disease, hypertension, and persons face increased risk of serious illness and complications and have been advised to stay home as much as possible, especially in the areas of community outbreak.

Some authorities have also issued sexual health guidelines for use during the pandemic like recommendations to have sex only with someone you live with, and who does not have the virus or symptoms of the virus.

\section{E. Self-isolation}

Self-isolation at home has been recommended for those diagnosed with COVID-19 and those who are 
suspected to be infected. Many governments have mandated or recommended self-quarantine for entire populations living in affected areas. The strongest self-quarantine instructions have been issued to those in high risk groups and those who may have been exposed to someone with COVID-19 and those who have recently travelled to a country or region with widespread transmission have been advised to self-quarantine for 14 days from the time of last possible exposure. Experiences prove that self-isolation must be for a period of 28 days, since some of them have been tested positive after this time period.

\section{MANAGEMENT}

\section{A. Containment and Mitigation}

Strategies to control an outbreak are containment or suppression, and mitigation. Containment can be undertaken only in the early stages of the outbreak and is aimed to trace and isolate those infected as well as to introduce other measures of infection control. When it is no longer possible to contain the spread of the disease, then efforts are to move to mitigation, where measures are taken to slow the spread and mitigate its effects on the healthcare system and society. A combination of both containment and mitigation measures may be undertaken at the same time (52).

\section{B. Contact tracing}

Contact tracing is an important method undertaken by the health authorities to determine the source of an infection and to prevent further transmission (53). Several mobile apps have been implemented or proposed for voluntary use. On 10 April 2020 Google and Apple jointly announced an initiative for privacy-preserving contact tracing based on Bluetooth technology and cryptography (54).

\section{Health Care}

Increasing capacity and adapting healthcare for the needs of COVID-19 patients was described by the $\mathrm{WHO}$ as a fundamental outbreak response measure. WHO also have issued guidelines for hospitals and primary healthcare services for shifting of resources at multiple levels, including focusing laboratory services towards COVID-19 testing, cancelling elective procedures whenever possible, separating and isolating COVID-19 positive patients, and increasing intensive care capabilities by training personnel and increasing the number of available ventilators and beds
$(55,56)$

\section{TREatment}

As of now no antiviral treatments are present. Antiviral drugs and medications targeting the immune response are under investigation (57) but none have proved to be effective. Remdesivir, have some effect on the time taken to be free of virus. At present the patients are provided with drinking fluids, resting and foods to boost the immune system. Severely ill patients are also provided with oxygen therapy and intravenous fluids required

\section{ACKNOWLEDGMENT}

I thank, B. Ali Sabrin, District Youth Coordinator, Nehru Yuva Kendra, Thiruvananthapuram, Ministry of Youth Affairs and Sports, Govt. of India for being the motivation and inspiration for writing this review article.

\section{REFERENCES}

[1] Definition of Coronavirus by Merriam-Webster". Merriam-Webster.

[2] Tyrrell DA and Fielder M (2002). Cold Wars: The Fight Against the Common Cold. Oxford University Press. p. 96. ISBN 978-0-19-263285-2.

[3] International Committee on Taxonomy of Viruses (ICTV). October 2018

[4] "ICTV Taxonomy history: Orthocoronavirinae". International Committee on Taxonomy of Viruses (ICTV).

[5] Fan Y, Zhao K, Shi ZL, Zhou P (March 2019). "Bat Coronaviruses in China". Viruses. 11 (3):210. doi:10.3390/v11030210.

[6] de Groot RJ, Baker SC, Baric R, Enjuanes L, Gorbalenya AE, Holmes KV, Perlman S, Poon L, Rottier PJ, Talbot PJ, Woo PC, Ziebuhr J (2011). "Family Coronaviridae". In King AM, Lefkowitz E, Adams MJ, Carstens EB, International Committee on Taxonomy of Viruses, International Union of Microbiological Societies. Virology Division (eds.). Ninth Report of the International Committee on Taxonomy of Viruses. Oxford: Elsevier. pp. 806-28.

[7] International Committee on Taxonomy of Viruses (2010-08-24). "ICTV Master Species List 2009—v10".

[8] Wertheim JO, Chu DK, Peiris JS, Kosakovsky Pond SL, Poon LL (June 2013). "A case for the ancient origin of coronaviruses". Journal of Virology. 87 (12): 7039-45.

[9] M (January 2017). "Molecular Evolution of Human Coronavirus Genomes". Trends in Microbiology. 25 (1): 35-48.

[10] Gouilh MA, Puechmaille SJ, Gonzalez JP, Teeling E, Kittayapong P, Manuguerra JC ."SARS-Coronavirus ancestor's foot-prints in South-East Asian bat colonies and the refuge theory". Infection, Genetics and Evolution. 11 (7): 1690-702.

[11] Cui J, Han N, Streicker D, Li G, Tang X, Shi Z, et al. "Evolutionary relationships between bat coronaviruses and their hosts". Emerging Infectious Diseases. 13 (10): 1526-32.

[12] Goldsmith CS, Tatti KM, Ksiazek TG, Rollin PE, Comer JA, Lee WW, et al. (February 2004). "Ultrastructural characterization of SARS coronavirus". Emerging Infectious Diseases. 10 (2): 320-26. 
[13] Neuman BW, Adair BD, Yoshioka C, Quispe JD, Orca G, Kuhn P, et al. (August 2006). "Supramolecular architecture of severe acute respiratory syndrome coronavirus revealed by electron cryomicroscopy". Journal of Virology. 80 (16): 7918-28.

[14] Fehr AR, Perlman S (2015). "Coronaviruses: an overview of their replication and pathogenesis". In Maier HJ, Bickerton E, Britton P (eds.). Coronaviruses. Methods in Molecular Biology. 1282. Springer. pp. 1-23.

[15] Lai MM, Cavanagh D (1997). "The molecular biology of coronaviruses". Advances in Virus Research. 48: 1-100.

[16] Cavanagh D, Mawditt K, Sharma M, Drury SE, Ainsworth HL, Britton P, Gough RE (August 2001). Schmidt A, Weber $\mathrm{O}$, Wolff $\mathrm{MH}$ (eds.). "Detection of a coronavirus from turkey poults in Europe genetically related to infectious bronchitis virus of chickens". Avian Pathology. Birkhäuser Advances in Infectious Diseases BAID. Birkhäuser. 30 (4): 355-68.

[17] Neuman, Benjamin W.; Kiss, Gabriella; Kunding, Andreas H.; Bhella, David; Baksh, M. Fazil; Connelly, Stephen; Droese, Ben; Klaus, Joseph P.; Makino, Shinji; Sawicki, Stanley G.; Siddell, Stuart G. (April 2011). "A structural analysis of $\mathrm{M}$ protein in coronavirus assembly and morphology". Journal of Structural Biology. 174 (1): 11-22.

[18] Chang CK, Hou MH, Chang CF, Hsiao CD, Huang TH (March 2014). "The SARS coronavirus nucleocapsid protein-forms and functions". Antiviral Research. 103: 39-50.

[19] Neuman BW, Kiss G, Kunding AH, Bhella D, Baksh MF, Connelly S, et al. (April 2011). "A structural analysis of M protein in coronavirus assembly and morphology". Journal of Structural Biology. 174 (1): 11-22.

[20] Coronavirus disease 2019 (COVID-19)-Symptoms and causes". Mayo Clinic.

[21] Hui DS, I Azhar E, Madani TA, Ntoumi F, Kock R, Dar O, et al. (February 2020). "The continuing 2019-nCoV epidemic threat of novel coronaviruses to global health-The latest 2019 novel coronavirus outbreak in Wuhan, China". Int J Infect Dis. 91: 264-268.

[22] "WHO Director-General's opening remarks at the media briefing on COVID-19". World Health Organization (WHO) (Press release). 11 March 2020.

[23] Simmons G, Zmora P, Gierer S, Heurich A, Pöhlmann S (December 2013). "Proteolytic activation of the SARS-coronavirus spike protein: cutting enzymes at the cutting edge of antiviral research". Antiviral Research. 100 (3): 605-14.

[24] Fehr AR, Perlman S (2015). "Coronaviruses: an overview of their replication and pathogenesis". In Maier HJ, Bickerton E, Britton P (eds.). Coronaviruses. Methods in Molecular Biology. 1282. Springer. pp. 1-23.

[25] Sexton NR, Smith EC, Blanc H, Vignuzzi M, Peersen OB, Denison MR (August 2016). "Homology-Based Identification of a Mutation in the Coronavirus RNA-Dependent RNA Polymerase That Confers Resistance to Multiple Mutagens". Journal of Virology. 90 (16): 7415-28.

[26] Lauer, Stephen A.; Grantz, Kyra H.; Bi, Qifang; Jones, Forrest K.; Zheng, Qulu; Meredith, Hannah R.; Azman, Andrew S.; Reich, Nicholas G.; Lessler, Justin (10 March 2020). "The Incubation Period of Coronavirus Disease 2019 (COVID-19) From Publicly Reported Confirmed Cases: Estimation and Application". Annals of Internal Medicine.

[27] Report 9: Impact of non-pharmaceutical interventions (NPIs) to reduce COVID-19 mortality and healthcare demand" (PDF). Imperial College COVID-19 Response Team. 16 March 2020.
[28] Mizumoto, Kenji; Kagaya, Katsushi; Zarebski, Alexander; Chowell, Gerardo (2020). "Estimating the asymptomatic proportion of coronavirus disease 2019 (COVID-19) cases on board the Diamond Princess cruise ship, Yokohama, Japan, 2020" (PDF). Euro Surveillance. 25 (10).

[29] Kuba, K.; Imai, Y.; Rao, S.; Gao, H.; Guo, F.; Guan, B.; Huan, Y.; Yang, P.; Zhang, Y.; Deng, W.; et al. A crucial role of angiotensin converting enzyme 2 (ACE2) in SARS coronavirus-induced lung injury. Nat. Med. 2005, 11, 875-879.

[30] Glowacka, I.; Bertram, S.; Muller, M.A.; Allen, P.; Soilleux, E.; Pfefferle, S.; Steffen, I.; Tsegaye, T.S.; He, Y.; Gnirss, K.; et al. Evidence that TMPRSS2 Activates the Severe Acute Respiratory Syndrome Coronavirus Spike Protein for Membrane Fusion and Reduces Viral Control by the Humoral Immune Response. J. Virol. 2011, 85, 4122-4134.

[31] Heurich, A.; Hofmann-Winkler, H.; Gierer, S.; Liepold, T.; Jahn, O.; Pohlmann, S. TMPRSS2 and ADAM17 Cleave ACE2 Differentially and Only Proteolysis by TMPRSS2 Augments Entry Driven by the Severe Acute Respiratory Syndrome Coronavirus Spike Protein. J. Virol. 2014, 88, 1293-1307.

[32] Shulla, A.; Heald-Sargent, T.; Subramanya, G.; Zhao, J.; Perlman, S.; Gallagher, T. A Transmembrane Serine Protease Is Linked to the Severe Acute Respiratory Syndrome Coronavirus Receptor and Activates Virus Entry. J. Virol. 2011, 85, 873-882.

[33] Zhou, P.; Yang, X.-L.; Wang, X.-G.; Hu, B.; Zhang, L.; Zhang, W.; Si, H.-R.; Zhu, Y.; Li, B.; Huang, C.-L.; et al. Discovery of a novel coronavirus associated with the recent pneumonia outbreak in humans and its potential bat origin. Microbiology 2020.

[34] Huang, C.; Wang, Y.; Li, X.; Ren, L.; Zhao, J.; Hu, Y.; Zhang, L.; Fan, G.; Xu, J.; Gu, X.; et al. Clinical features of patients infected with 2019 novel coronavirus in Wuhan, China. Lancet 2020, 395, 497-506.

[35] Hui DS, I Azhar E, Madani TA, Ntoumi F, Kock R, Dar O, et al. (February 2020). "The continuing 2019-nCoV epidemic threat of novel coronaviruses to global health-The latest 2019 novel coronavirus outbreak in Wuhan, China". Int J Infect Dis. 91: 264-66.

[36] Carod-Artal, FJ (1 May 2020). "Neurological complications of coronavirus and COVID-19". Revista de neurologia. 70 (9): 311-322.

[37] Long, B; Brady, WJ; Koyfman, A; Gottlieb, M (18 April 2020). "Cardiovascular complications in COVID-19". The American Journal of Emergency Medicine.

[38] Heymann DL, Shindo N, et al. (WHO Scientific and Technical Advisory Group for Infectious Hazards) (February 2020). "COVID-19: what is next for public health?". Lancet. Elsevier BV. 395(10224): 542-545.

[39] "Q \& A on COVID-19". European Centre for Disease Prevention and Control.

[40] Asadi, Sima; Wexler, Anthony; Cappa, Christopher; et al. (20 February 2019). "Aerosol emission and superemission during human speech increase with voice loudness" (PDF). Nature. 9(1): 2348. Bibcode:

[41] Loh NW, Tan Y, Taculod J, Gorospe B, Teope AS, Somani J, et al. (March 2020). "The impact of high-flow nasal cannula (HFNC) on coughing distance: implications on its use during the novel coronavirus disease outbreak". Canadian Journal of Anesthesia.

[42] van Doremalen N, Bushmaker T, Morris DH, Holbrook MG, Gamble A, Williamson BN, et al. (March 2020). "Aerosol and Surface Stability of SARS-CoV-2 as Compared with 
SARS-CoV-1". New England Journal of Medicine. 382 (16): 1564-7.

[43] COVID-19 and Our Communities -ACON - We are a New South Wales based health promotion organisation specialising in HIV prevention, HIV support and lesbian, gay, bisexual, transgender and intersex (LGBTI) health". Acon.org.au.

[44] Sex and Coronavirus Disease 2019 (COVID-19)" (PDF). nyc.gov. 27 March 2020.

[45] Mathrubhumi.com. Press release. 8 May 2020.

[46] "Curetis Group Company Ares Genetics and BGI Group Collaborate to Offer Next-Generation Sequencing and PCR-based Coronavirus (2019-nCoV) Testing in Europe". GlobeNewswire News Room. 30 January 2020.

[47] Cellex Emergency Use Authorization". FDA. 1 April 2020.

[48] Will an Antibody Test Allow Us to Go Back to School or Work?". New York Times.

[49] "Developing Antibodies and Antigens for COVID-19 Diagnostics". Technology Networks. 6 April 2020. Retrieved 30 April 2020.

[50] Symptom-Based Strategy to Discontinue Isolation for Persons with COVID-19 (2020) referenced a) CDC unpublished data, b) Wölfel et al. (2020).

[51] Coronavirus Disease 2019 (COVID-19)". US Centers for Disease Control and Prevention. 11 February 2020.

[52] Baird RP (11 March 2020). "What It Means to Contain and Mitigate the Coronavirus". The New Yorker.

[53] "Expert interview: What is contact tracing?". Blog: Public Health Matters. Public Health England, Government of the United Kingdom.

[54] "Apple and Google are launching a joint COVID-19 tracing tool for iOS and Android". TechCrunch.

[55] "Hospital readiness checklist for COVID-19". euro.who.int. 25 March 2020.

[56] Checklist for hospitals preparing for the reception and care of coronavirus 2019 (COVID-19) patients (Report). European Centre for Disease Prevention and Control. 26 February 2020.

[57] Sanders JM, Monogue ML, Jodlowski TZ, Cutrell JB (April 2020). "Pharmacologic Treatments for Coronavirus Disease 2019 (COVID-19): A Review".
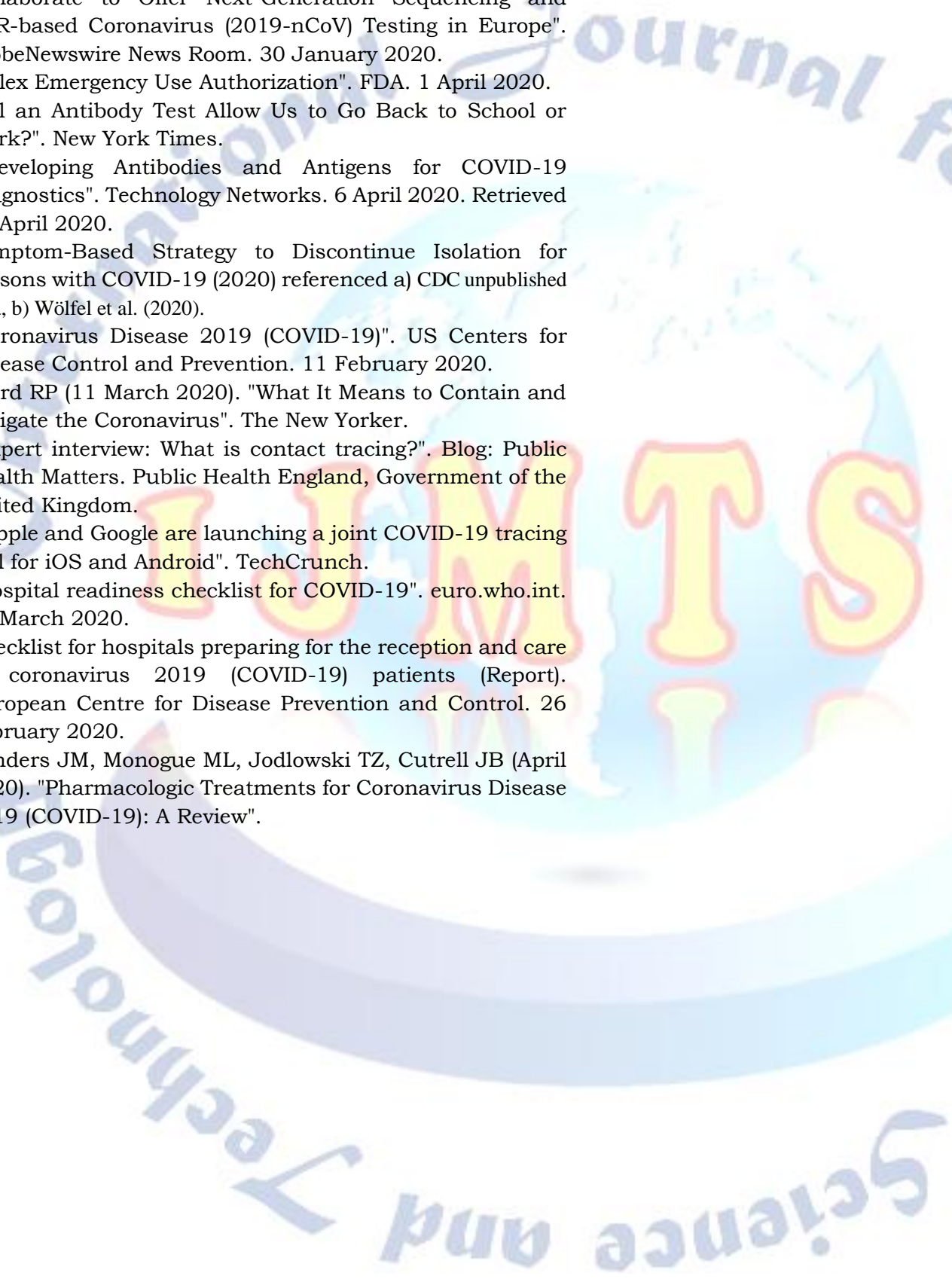